\title{
The Biomass Supply Chain Network Auto- Regressive Moving Average Algorithm
}

\author{
Mostafa Esmaeili Shayan*(D), Gholamhassan Najafi***(D), Abbas Nazari***(iD) \\ * Ph.D. Student in Renewable Energy Engineering, Tarbiat Modares University, Tehran, Iran \\ ** Associate Professor, Mechanics of Biosystems Engineering Department, Tarbiat Modares University, \\ Tehran, Iran \\ *** MSc in Information Technology Management, Islamic Azad University, Science and Research \\ Branch, Tehran, Iran \\ (Mostafa.Esmaeili@modares.ac.ir, g.najafi@modares.ac.ir, abbas.nazari@ srbiau.ac.ir) \\ $\$$ Corresponding Author; Gholamhassan Najafi, 14115-336, Tel: +982148292004, \\ Fax: +982148292004, g.najafi@modares.ac.ir
}

Received: 24.01.2021 Accepted:02.02.2021

\begin{abstract}
Renewable power plants contribute almost insignificantly in the country's electricity supply. Due to the environmental uncertainty and the rapid development of modern technology in the recent century, it is usually necessary to predict future situations using insufficient data over a short period. Renewable fuels and biofuels as a significant replacement for fossil fuels have been of great interest in recent decades. Optimum design of supply chains is an essential requirement for the commercial production of biofuels. This research has employed mathematical optimization and a mixed integrated linear programming (MILP) approach for the feedstock pathway to the fuel supply chain (BSC) scenario. The further examination includes the effect of the autoregressive moving average (ARMA) time series structure for the demand of biofuels on the design of the supply chain. After developing the model, a numerical example of 8 years was used in the supply chain to gain a wider perspective. The results showed that the optimal cost can be determined and 4 valid locations were adopted out of 10 proposed refinery building sites. Finally, it evaluates and validates the proposed model with experimental results.
\end{abstract}

Keywords Renewable, Fuel Supply Chain, Time Series, Biomass, Biofuels.

\section{Introduction}

Energy consumption has increased in the world and particularly in industrialized countries, due to changes in lifestyle and population growth. In addition to various social and environmental problems associated with the use of fossil fuels, the non-renewability of these fuels [1] has raised concerns about energy consumption. In recent years, the production of biofuels has been raised as a promising solution to this problem, which has attracted the attention of many researchers for developing the supply chain of such fuels [2]. Biomass as raw material, including agricultural wastes (consisting of plant and animal matter), forest products, and municipal and industrial wastes, is used for the production of biofuels and the generation of heat and electricity in the bioenergy supply chain[3].

Biomasses can be extracted from many materials. Biomass has been around for three generations. Their earliest generation was extracted from oilseeds and sugar plants. Biomasses can be extracted from many materials. Biomass has been around for three generations. Their earliest generation was extracted from oilseeds and sugar plants. The big conflict of this generation of biofuels is its users. For oilseeds and sugar plants, there are applications (first generation biomass) in human food, animal feed and fuel industry raw material. Therefore, the use of non-edible raw materials has increased in the production of biofuels. However, the use of non-edible raw materials is facing many challenges[4]. Biomass raw materials for the second generation of fuels include lignocellulosic biomass, agricultural waste, and wood waste and products. Algae are non-edible raw materials that have recently been introduced as the third-generation biomass for biofuel production. Today, there is controversy regarding making a decision on the use of land for the cultivation of food products or the first generation of raw materials. So researchers are now studying the lignocellulosic biomass raw 
materials to address these problems[5]. Biomass is harvested from agricultural land and initial transportation preparation measures are taken at the sites. These acts may include chopping, cutting, packaging, measuring, etc. In later stages the biomass can be processed in tanks or outside and transported to a refinery afterwards[6]. There may be a prerefinery and preparation process at this stage. Reactor palletizing and transfer is a recent method in the supply chain and is used in advanced systems. The refinery fuel can be used in domestic, industry, car and power stations[7]. Figure 1 shows the biofuel supply chain (BSC).

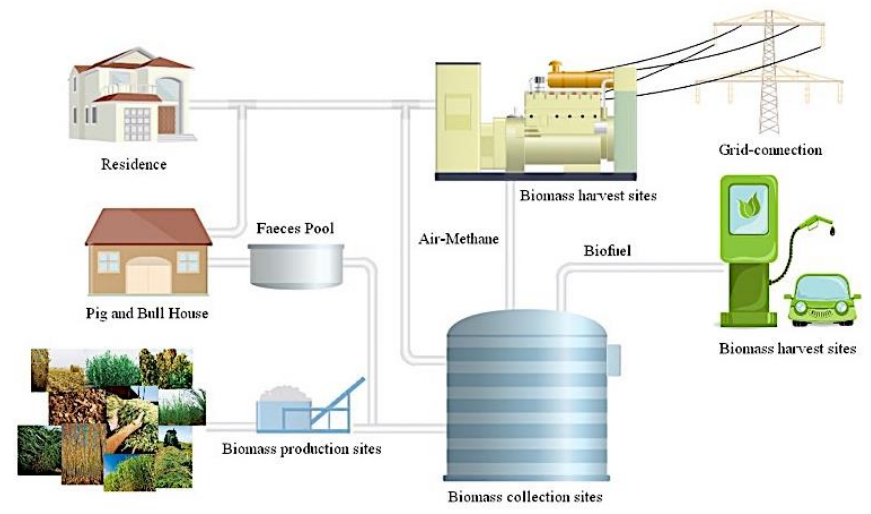

Fig. 1. Biofuel supply chain (BSC) and its applications.

In the biofuel supply chain, decision variables and sequential activities exist. Land selection, planting, fertilization and spraying, harvesting, preparation, transportation to storage tanks, refineries and production processes for biofuels are available in this chain. Currently, mathematical models can study and develop optimization models variables with a variety of variations with software and intensive decision support systems (DSS). The wheat farm has a high biomass production yield, but it has a high rental cost[8]. In addition, as the planting time and method are interdependent, different scenarios need to be considered together. Mathematical optimization and the Mixed Integrated Linear Programming approach (MILP) are one of the most well-known fuel supply chain (BSC) modelling methods in the network design scenario. The localization of facilities is considered one of the critical goals for using MILP models. Decision variables in the localization of facilities can be considered as binary form either technologically or the capacity used in a facility. Because the design of a BSC network affects biomass logistics, the chain decision-makers simultaneously optimize the design of the BSC network and the flow of materials between facilities[9]. In this regard, they have developed the MILP and simultaneously optimize the design of the BSC network; thereby, they have found the flow of materials between the facilities[10,11]. Mole et al. were the first to develop the MILP model in which the location of processing sites was optimized by minimizing biomass logistic costs[12]. Strategic planning of the BSC, optimum biomass allocation based on uncertain localization decisions[13], and optimal design and production of bioethanol supply chain are some examples of MILP models in the BSC network design[14].

The main obstacle to the biofuel commercialization is its complex production processes. This complexity comes from different forms of various parameters, including uncertainty as one of the common forms of variation in the BSC parameters. The supply of biomass raw material, biofuel production and demand, price, and logistics are the standard parameters associated with the uncertainty. The study of MILP models allows us to observe many studies related to the optimization models for the BSC network design under uncertainty[15]. Dalmas et al. [16], for example, designed a random dynamic MILP model for designing a BSC under market uncertainty conditions. Giarola et al. proposed a multi-period multidimensional MILP model for optimization of bioethanol supply chain network design by taking the biomass and carbon market uncertainties into account[17].

Time series data are another form of variables defined as a sequence of numerical data in repeated orders, usually occurring at uniform intervals[18]. As a time series model, ARMA has provided management insights into the supply chain dynamics[19]. A multilevel supply chain model based on the ARIMA time series models was proposed by Gilbert [20], who first used the general class of ARIMA time series models for modeling customer demand in the supply chain, and recommended the ARIMA models for time series orders and inventory[21]. The bullwhip effect phenomenon is also discussed by this model, the effect of which on the supply chain was also investigated by Lee et al. Supply chain performance is affected by prediction accuracy. Precision predictive systems are of high value in a chain[22]. Globalization will lead to supply chain complexity and imbalances. Chan et al. investigated the impact of fuzzy time series prediction systems on a supply chain with disturbances[23]. They also showed that an excellent method to fit with ARMA models is to use fuzzy time series with higher levels. The time series forecasting plays a central role in risk management, portfolio selection, asset valuations, option pricing, and hedging strategies in modern Finance.

The rest of this article is organized as follows. The problem definition is expressed in the next section. In mathematical modeling, the proposed approach modeling is expressed step by step, followed by a description of the ARMA model. In the next section, the proposed model is run on a numerical example. A final validation with conclusions and suggestions are presented in the end.

\section{Materials and Method}

\subsection{Problem Definition}

Table 1 lists the indices, sets, parameters, and decision variables. This research considers a four-level BSC. The biomass can be cultivated in supply regions $i$ on existing marginal lands not used for other agricultural purposes. In this research, the harvest method is assumed to be in the form of square bales. After harvesting, the biomass product is transferred to storage depots located in $j$ regions. Biomass storage in the warehouse will partially destroy it. After storage, the biomass product is transported by a truck from the warehouse, $i$, to the refinery, $r$, for conversion into biofuels, and the produced fuel is then shipped to the demand site, $k$. the proposed mathematical model aims to minimize the total 
biofuel supply chain cost by determining the optimal levels of decision variables.

\subsection{Assumptions of the Problem}

The assumptions of the proposed model are as follows:

- Biomass harvesting is assumed as a large square bale of $397 \mathrm{~kg}$ with easy transportation and storage[24,25].

- Studies show that multiple harvests over a year reduce total biomass production due to the weakening of the root. Therefore, one harvest (one-year periods) immediately after the first cold season is used in this model as it is known as the most eco-friendly and cost-effective harvesting method in the reference [26].

Since road transport is available in all regions, only trucks and trailers are considered for the road transport of biomass and biofuel, respectively, in this research.

- It is assumed that per capita demand for biofuels is determined and definite in each demand region.

\subsection{Mathematical Modeling}

A MILP model is proposed to minimize the total cost of a BSC network by determining optimum levels of decision variables. The objective function (Eq. 1) minimizes the total cost of a BSC and includes nine parts. The first part calculates the cost of marginal land lease in all supply sites over all periods. The second and third parts refer to the cost of biomass cultivation and harvesting in all supply sites $i$ at all times. The fourth part estimates biomass storage costs in all storehouses located in sites $j$ at all periods. The fifth to seventh parts respectively deal with the costs of biomass transportation from the supply sites $i$ to the storehouses located in areas $j$ and from storehouses to refineries in $r$ regions, and the transport of biofuels from these refineries to demand sites in $k$ areas at all periods. The eighth part calculates the fixed cost of installed refineries at all their capacity levels at all periods. And the ninth part of the objective function is related to the cost of biofuel production in refineries located in $r$ regions at all periods.

$$
\begin{aligned}
& \min Z=\sum_{i=1}^{I} \sum_{t=1}^{T} C_{i}^{t} Y_{i}^{t}+\sum_{i=1}^{I} \sum_{t=1}^{T} C u_{i}^{t} Y_{i}^{t}+\sum_{i=1}^{I} \sum_{t=1}^{T} \delta_{i}^{t} Y_{i}^{t}+\sum_{i=1}^{I} \sum_{j=1}^{J} \sum_{t=1}^{T} S_{j}^{t} S_{i j}^{t} \\
& +\sum_{i=1}^{I} \sum_{j=1}^{J} \sum_{t=1}^{T} \varphi_{i j}^{t} D_{i j} S_{i j}^{t}+\sum_{j=1}^{j} \sum_{r=1}^{R} \sum_{t=1}^{T} \alpha_{j r}^{t} D_{j r} V_{j r}^{t}+\sum_{r=1}^{R} \sum_{k=1}^{K} \sum_{t=1}^{T} \beta_{r k}^{t} D_{r k} N_{r k}^{t} \\
& +\sum_{r=1}^{R} \sum_{q^{\prime}=1}^{Q^{\prime}} \sum_{t=1}^{T} F_{r q^{\prime}}^{t} X_{r q^{\prime}}+\sum_{r=1}^{R} \sum_{t=1}^{T} W_{r}^{t} N_{r}^{t}
\end{aligned}
$$

Constraint 2 ensures that the marginal lands allocated for biomass cultivation do not exceed the maximum marginal lands available in each supply site $i$ at each period $t$.

$$
Y_{i}^{t} \leq M_{i} \quad \forall i, t
$$

Constraint 3 expresses that a maximum of one refinery (at all capacity levels of q') can be established at any location $r$.

$$
\sum_{q^{\prime}=1}^{Q^{\prime}} X_{r q^{\prime}} \leq 1 \quad \forall r
$$

Constraint 4 corresponds to the capacity of each storehouse and states that the amount of biomass stored in warehouse $j$ for any period $t$ should not exceed the maximum capacity of

\begin{tabular}{|c|c|}
\hline Symbols & Indices/Sets \\
\hline$i$ & Biomass supply sites $(i=1, \ldots, I)$ \\
\hline$j$ & Biomass storage locations $(j=1, \ldots, J)$ \\
\hline$r$ & Refinery location $(r=1, \ldots, R)$ \\
\hline$k$ & Biofuel demand sites $(k=1, \ldots, K)$ \\
\hline$q$ & Warehouse capacity levels $(q=1, \ldots, Q)$ \\
\hline$q^{\prime}$ & Refinery capacity levels $\left(q^{\prime}=1, \ldots, Q^{\prime}\right)$ \\
\hline$t$ & Time periods in the modeling horizon $(z=1, \ldots, T)$ \\
\hline \multicolumn{2}{|c|}{ Binary decision variables } \\
\hline $\mathrm{X}_{\mathrm{rq}}$ & $\left\{1\right.$, if a refinery with a capacity level of $q^{\prime}$ is established in site $r$; otherwise 0$\}$ \\
\hline \multicolumn{2}{|c|}{ Continuous decision variables } \\
\hline$Y_{i}^{t}$ & The marginal area used in the supply site $i$ at the period $\mathrm{t}(\mathrm{ha})$ \\
\hline$S_{i i}{ }^{t}$ & The amount of biomass sent from the supply site $i$ to the warehouse $j$ during the period t (tonne) \\
\hline$V_{j i}{ }^{t}$ & The amount of biomass sent from the warehouse $j$ to the refinery $r$ during the period $\mathrm{t}$ (tonne) \\
\hline$N_{r k}{ }^{t}$ & The volume of biofuels sent from the refinery $r$ to the demand site $k$ during the period $\mathrm{t}(l)$ \\
\hline$N_{r}{ }^{t}$ & The volume of biofuels produced by the refinery $r$ during the period $\mathrm{t}(l)$ \\
\hline \multicolumn{2}{|l|}{ Parameters } \\
\hline$C_{i}{ }^{t}$ & The annual cost of marginal land lease in the supply site $i$ during time $\mathrm{t}(\$ / h a)$ \\
\hline$C u_{i}{ }^{t}$ & The cost of biomass cultivation in the supply site $i$ during time $\mathrm{t}(\$ / h a)$ \\
\hline$\delta_{i}{ }^{t}$ & The cost of biomass harvest in the supply site $i$ during time $\mathrm{t}(\$ / h a)$ \\
\hline$S_{j}{ }^{t}$ & The cost of biomass storage in the warehouse $\mathrm{j}$ during time $\mathrm{t}(\$ /$ tonne $)$ \\
\hline$\varphi_{i j}{ }^{t}$ & The cost of biomass transportation from the supply site $i$ to the warehouse $j$ at time $\mathrm{t}(\$ /$ tonne $\times \mathrm{km})$ \\
\hline$D_{i j}$ & Distance between supply area $i$ and warehouse $j(\mathrm{~km})$ \\
\hline
\end{tabular}
the storehouse during that specified period.

$$
\sum_{i=1}^{I} S_{i j}^{t} \leq \sum_{q=1}^{Q} Q_{j q}^{t} \quad \forall j, t
$$

Table 1. Appearance properties of accepted manuscripts 


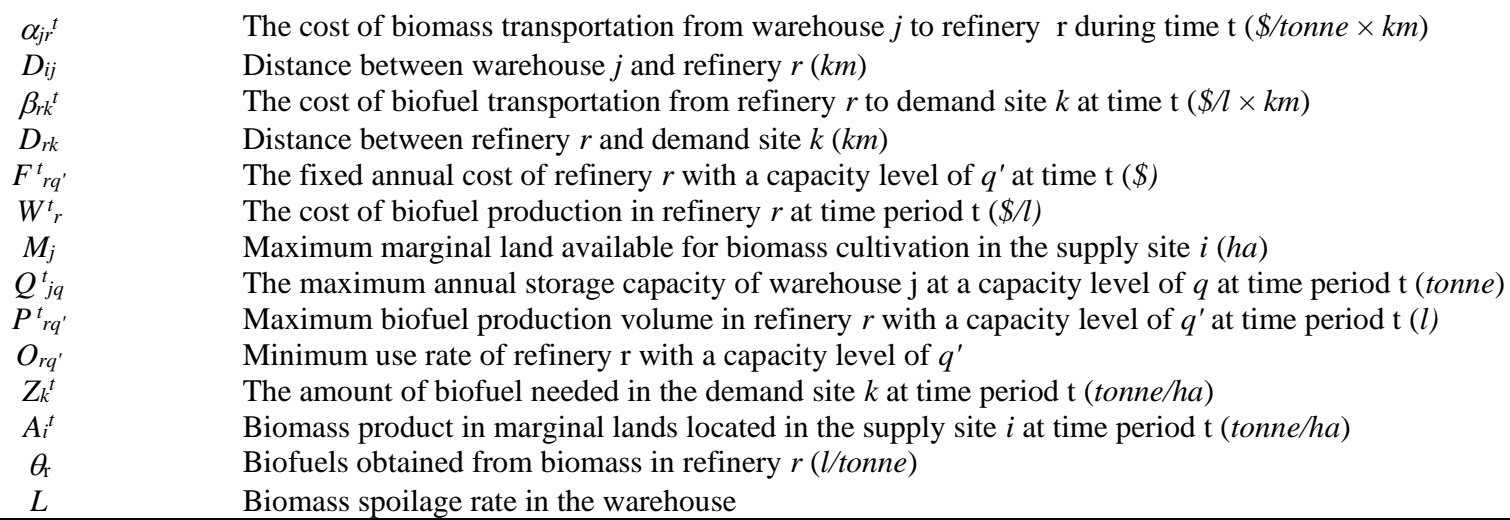

Constraint 5 ensures that a refinery at the capacity level of $q^{\prime}$ (if it is installed in site $r$ ) cannot produce biofuels more than its capacity at each period $t$.

$$
N_{r}^{t} \leq \sum_{q^{\prime}=1}^{Q^{\prime}} P_{r q^{\prime}}^{t} X_{r q^{\prime}} \quad \forall r, t
$$

Constraint 6 ensures that the amount of biofuel production in all refineries at each period exceeds the minimum rate of using the capacity of all refineries at that period.

$$
\sum_{r=1}^{R} N_{r}^{t} \geq \sum_{r=1}^{R} \sum_{q^{\prime}=1}^{Q^{\prime}} O_{r q^{\prime}} P_{r q^{\prime}}^{t} X_{r q^{\prime}}
$$

Constraint 7 states that during each period $t$, the production capacity of all refineries is greater than or equal to the amount of biofuel required in all demand sites $k$.

$$
\sum_{r=1}^{R} \sum_{q^{\prime}=1}^{Q^{\prime}} \boldsymbol{P}_{r q^{\prime}}^{t} \boldsymbol{X}_{r q^{\prime}} \geq \sum_{k=1}^{K} Z_{k}^{t}
$$

Constraint 8 indicates that the amount of biomass sent from each storehouse to all refineries at each period should not exceed its usable stored amount (considering biomass losses in the storehouse). The biomass harvested and stored in each the storehouse should be allocated to one or more refineries.

$$
\sum_{r=1}^{R} V_{j r}^{t} \leq \sum_{i=1}^{I} S_{i j}^{t}(1-L)
$$

$$
\forall j, t
$$

Constraint 9 ensures that the amount of biomass generated in the time horizon in each supply site $i$ at each period is equal to that sent and stored in the relevant storehouses at that period.

$$
A_{i}^{t} Y_{i}^{t}=\sum_{j=1}^{J} S_{i j}^{t}
$$$$
\forall i, t
$$

Constraint 10 states that the amount of biomass received from all storage depots by each refinery $r$ must be converted into biofuels throughout each period $t$.

$$
N_{r}^{t}=\sum_{j=1}^{J} \theta_{r} V_{j r}^{t}
$$

$$
\forall r, t
$$

Constraint 11 expresses that during each period $t$, the volume of biofuels sent from all refineries located in $r$ regions and assigned to each demand site $k$ should not be less than the biofuel requirement in that site.

$$
\sum_{r=1}^{R} N_{r k}^{t} \geq Z_{k}^{t} \quad \forall t, \mathrm{k}
$$

Constraint 12 ensures that at each period $t$ for each refinery, biofuels sent to all demand sites do not exceed those produced in that refinery at that period.

$$
\sum_{k=1}^{K} N_{r k}^{t} \leq N_{r}^{t} \quad \forall r, t
$$

Finally, constraints 13 and 14 describe the nature of decision variables used in the model.

$$
\begin{array}{ll}
X_{r q^{\prime}} \in\{0,1\}, & \forall r, q^{\prime} \\
S_{i j}^{t}, V_{i r}^{t}, Y_{i}, N_{r k}^{t}, N_{r}^{t} \geq 0 & \forall i, j, \mathrm{r}, \mathrm{k}, t
\end{array}
$$

\subsection{The ARMA Model}

The ARMA model is often used to measure time series data and can be used to predict the future values of these series. This model comprises two parts of autoregressive (A.R.) and moving average (M.A.) shown as $\mathrm{p}$ and $\mathrm{q}$ degrees, respectively, in the model. Equation 15 shows the general form of the ARMA $(p, q)$ model.

$$
Z_{t}=c+\varepsilon_{t}+\sum_{i=1}^{p} \varphi_{i} Z_{t-i}+\sum_{i=1}^{q} \theta_{i} \varepsilon_{t-i}
$$

In Equation 15, $\varphi_{i}$ and $\theta_{i}$, are the model parameters, $\mathrm{c}$ is a constant, and $\varepsilon_{t}$ is the model error at period $t$. If the time series data are not stable, ARMA (p,d,q) model is used instead of ARIMA $(p, q)$, where $d$ is the number of differentiation times to stabilize data. If $d$ equals zero, the ARIMA model will change into ARMA. The Box-Jenkins method is used to estimate the ARIMA and ARMA models, which includes the following steps:

1) Identification: At this stage, several models are selected from the ARIMA models meaning that sample values for $\mathrm{p}$ and $\mathrm{q}$ are determined by considering autocorrelation and partial autocorrelation functions.

2) Estimation: In this step, the model (or models) selected for the first time are processed on the data to estimate the parameters. 
3) Evaluation: The desirability of the model selected in the first round and estimated in the second round is evaluated at the last stage based on criteria considered for the same purpose [27].

To select the optimal model, some criteria were presented by the researchers. In this research, the Schwarz Bayesian Criterion (SBC) is used to choose the best model with a minim SBC. It is also assumed that the demand for biofuels follows the ARMA (p,q) pattern. Using the ARMA model, therefore, the demand relationship is estimated to predict the demand for the subsequent periods. Then, the surface areas of applied marginal regions, locations, the optimum production volume of refineries, and optimal flow in the chain for subsequent periods were determined based on the predicted data using the proposed model for the BSC.

\subsection{Numerical Example}

In this section, a numerical example is presented to analyze the presented model based on the ARMA demand. Ten supply sites are considered for biomass cultivation, and a biomass collection center is located on each site. Each area is also a potential site for the establishment of a refinery, and the model determines the optimal location of refiners. It is assumed that the refineries must supply biofuels in these ten areas.

\subsection{Input Parameters}

The following assumptions are considered for this numerical example:

1) The modeling horizon is 32 years and each year is assumed to be a time period $(t=1, \ldots, 32)$.

2) Ten sections are considered as potential sites for the biomass cultivation $(i=1, \ldots, 10)$, available storage locations $(j$ $=1, \ldots, 10)$, potential sites for the construction of a refinery $(r$ $=1, \ldots, 10)$, and the biofuel demand site $(k=1, \ldots, 10)$.

3) No seasonal effects are assumed for all periods.

4) It is assumed that the population ratio is constant in different years during the time horizon and the demand of each region is proportional to the population of that area.

5) All costs are considered constant during the time horizon.

The problem input parameters are presented in Tables 2 and 3.

Table 2. Values of input parameters $\left(C_{i}^{t}, A^{t}, M_{i}\right)$

\begin{tabular}{lllll}
\hline Area $(i)$ & Population & $\begin{array}{l}C_{i}^{t}(\$ / h a) \\
\text { per } t\end{array}$ & $\begin{array}{l}A_{i}^{t_{i}(\text { tonne/ha })} \\
\text { per } t\end{array}$ & $M_{i}(\mathrm{ha})$ \\
\hline 1 & 13937 & 28.4 & 17.2 & 33508 \\
2 & 11119 & 29.6 & 17 & 33116 \\
3 & 16321 & 53.1 & 20.2 & 29425 \\
4 & 66861 & 25.9 & 18.1 & 29021 \\
5 & 8962 & 28.4 & 16.4 & 24821 \\
6 & 3993 & 27.2 & 16.7 & 24725
\end{tabular}

\begin{tabular}{lllll}
7 & 21100 & 39.5 & 17.1 & 24066 \\
8 & 11451 & 29.6 & 17.5 & 23556 \\
9 & 2246 & 28.4 & 15.3 & 23023 \\
10 & 6429 & 32.1 & 17.1 & 21623 \\
\hline
\end{tabular}

Table 3. Values of other key input parameters

\begin{tabular}{|c|c|c|}
\hline Parameter & Unit & Value \\
\hline$C u_{i}^{t}$ & $(\$ / h a)$ & 395 (for each $i$ and $t$ ) \\
\hline$\delta_{i}{ }^{t}$ & $(\$ / h a)$ & $27.9($ for each $i$ and $t$ ) \\
\hline$S_{j}^{t}$ & $(\$ /$ tonne $)$ & 21.7 (for each $i$ and $t$ ) \\
\hline$\varphi_{i j}{ }^{t}$ & $(\$ /$ tonne $\times \mathrm{km})$ & 0.18 (for each $i, r$, and $t$ ) \\
\hline$\alpha_{j r}^{t}$ & $(\$ /$ tonne $\times \mathrm{km})$ & 0.18 (for each $i, r$, and $t$ ) \\
\hline$\beta_{r k}^{t}$ & $(\$ / l \times k m)$ & 0.000028 (for each $r, k$, and $t$ ) \\
\hline$F^{t}{ }_{r q^{\prime}}$ & $(\$)$ & $\begin{array}{l}39000,000 \text { (for each } r, t \text { and q' }=1 \text { ); } \\
\text { a refinery with an MLPY capacity } \\
\text { of } 760\end{array}$ \\
\hline$F^{t}{ }_{r q^{\prime}}$ & $(\$)$ & $\begin{array}{l}72000,000 \text { (for each } r, t \text { and q' }=2 \text { ); } \\
\text { a refinery with an MLPY capacity } \\
\text { of } 1520\end{array}$ \\
\hline$W^{t} r$ & $(\$ / l)$ & $0.2($ for each $i$ and $t$ ) \\
\hline$Q_{j q}^{t_{j q}}$ & (tonne) & 1511975 (for each $j, q$, and $t$ ) \\
\hline$P_{r q}^{t}$ & $(l)$ & $\begin{array}{l}760,000,000 \text { (for each } r, t \text { and q' }= \\
\text { 1) }\end{array}$ \\
\hline$P_{r q}^{t}$ & $(l)$ & $\begin{array}{l}1,520,000,000 \text { (for each } r, t \text { and q' } \\
=2 \text { ) }\end{array}$ \\
\hline$O_{r q^{\prime}}$ & - & 0.88 (for each $r$ and $q^{\prime}$ ) \\
\hline$\theta_{\mathrm{r}}$ & (l/tonne) & $313($ for each $r$ ) \\
\hline$L$ & - & 0.028 \\
\hline
\end{tabular}

\section{Results}

The proposed MILP model was first run with GAMS software based on the numerical example data to demonstrate its potential implementation for real examples. The software output for these data is as follows:

The optimal BSC cost is $\$ 43,655,500,000$, and of the ten potential locations for the construction of a refinery, it selects four sites as optimal locations and installs three refineries at the first capacity level in the first, third, and eighth sections, and one refinery at the second capacity level in the fourth section (Table 4).

Table 4. Optimal locations of refineries with actual data

\begin{tabular}{lll}
$X_{r q} q^{\prime}=1$ & $q^{\prime}=2$ \\
\hline
\end{tabular}




$$
\begin{aligned}
& r=1 \\
& r=3 \\
& r=4 \\
& r=8
\end{aligned}
$$$$
*
$$

The modeling horizon in this problem is assumed to be 32 years, and the demand data form a time series within 32 years, the values of which can be predicted through ARMA modeling for the next years. For demand, therefore, ARMA modeling was implemented through Eviews 8 software. The results indicate that the data considered for demand follow the ARMA (2,1) process (Equation 16).

$$
Z_{t}=c+\varepsilon_{t}+\varphi_{1} Z_{t-1}+\varphi_{2} Z_{t-2}+\theta_{1} \varepsilon_{t-1}
$$

Relationships $17-26$ is the ARMA equations considered in the numerical examples for ten sections.

$$
{ }_{1} i=Z_{t}=105000000+2.08 Z_{t-1}-1.09 Z_{t-2}+\varepsilon_{t}-1.55 \varepsilon_{t-1}
$$

$2 i=Z_{t}=83793584+2.08 Z_{t-1}-1.09 Z_{t-2}+\varepsilon_{t}-1.55 \varepsilon_{t-1}$

${ }_{3} i=Z_{t}=123000000+2.08 Z_{t-1}-1.09 Z_{t-2}+\varepsilon_{t}-1.55 \varepsilon_{t-1}$

${ }_{4} i=Z_{t}=504000000+2.08 Z_{t-1}-1.09 Z_{t-2}+\varepsilon_{t}-1.55 \varepsilon_{t-1}$

${ }_{5} i=Z_{t}=67538276+2.08 Z_{t-1}-1.09 Z_{t-2}+\varepsilon_{t}-1.55 \varepsilon_{t-1}$

${ }_{6} i=Z_{t}=30091535+2.08 Z_{t-1}-1.09 Z_{t-2}+\varepsilon_{t}-1.55 \varepsilon_{t-1}$

${ }_{7} i=Z_{t}=159000000+2.08 Z_{t-1}-1.09 Z_{t-2}+\varepsilon_{t}-1.55 \mathcal{E}_{t-1}$

${ }_{8} i=Z_{t}=86295559+2.08 Z_{t-1}-1.09 Z_{t-2}+\mathcal{E}_{t}-1.55 \mathcal{E}_{t-1}$

${ }_{9} i=Z_{t}=16926017+2.08 Z_{t-1}-1.09 Z_{t-2}+\mathcal{E}_{t}-1.55 \mathcal{E}_{t-1}$

${ }_{10} i=Z_{t}=48449406+2.08 Z_{t-1}-1.09 Z_{t-2}+\varepsilon_{t}-1.55 \varepsilon_{t-1}$

Through the ARMA process, the demand values were predicted for eight periods after the time horizon, and the presented MILP model was re-run for these data. The software output will predict the optimum locations of biomass supply, the optimal location and production of refiners, and the optimal flow between different chain levels in the next eight periods. The output obtained from the model through GAMS software is as follows:

The estimated optimal cost for the supply chain is $\$$ $185,433,000,000$ which selects four locations as optimal places out of the ten potential sites for the refinery construction and establishes two first-capacity level refineries in the third and eighth sections and two second-capacity level refineries in the first and fourth sections (Table 5).

Table 5. Optimal locations of the refineries with predicted data

\begin{tabular}{crc}
\hline$X r q^{\prime}$ & $q^{\prime}=1$ & $q^{\prime}=2$ \\
\hline$r=1$ & & $*$ \\
$r=3$ & $*$ & \\
$r=4$ & & $*$ \\
$r=8$ & $*$ & \\
\hline
\end{tabular}

\subsection{Validation}

The BSC model proposed in this paper was used for a numerical example, and then validated in two steps using the reproduction behavior test [28]. The ARMA model parameters were first estimated using the data of all periods. The second step compared changes in the first part demand for the period $t=32$ to $t=4$ in two actual and predicted values using the ARMA process. A comparison of the results of actual data with those predicted through the proposed ARMA model (Fig. 2) reveals the model's quantitative validity.

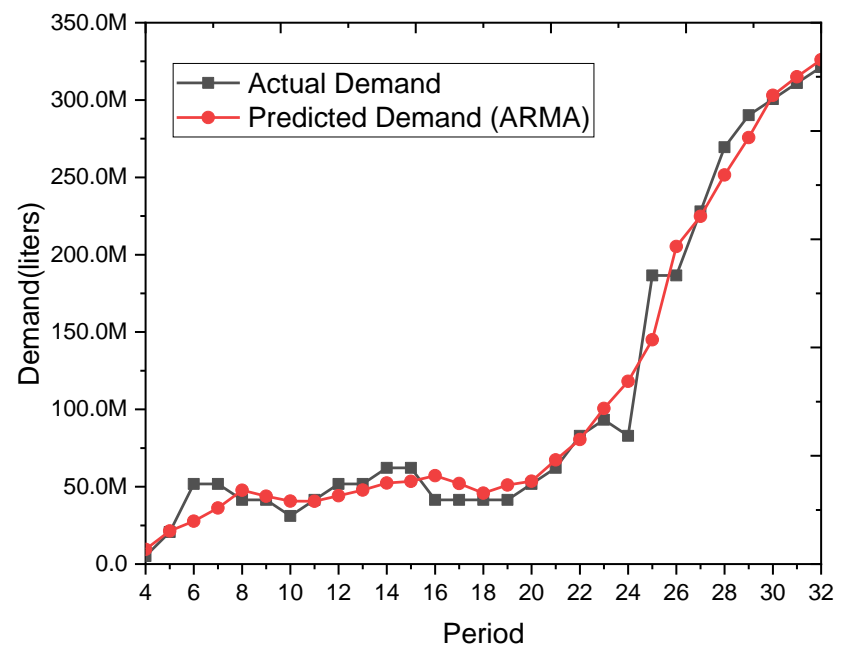

Fig. 2. The trend of demand changes in both real and predicted situations

\section{Conclusion}

In the statistical analysis of time series, autoregressive moving average models provide a parsimonious description of a stationary stochastic process in terms of two polynomials, one for the autoregression and the second for the moving average. Finding appropriate values of $p$ and $q$ in the ARMA $(\mathrm{p}, \mathrm{q})$ model can be facilitated by plotting the partial autocorrelation functions for an estimate of $\mathrm{p}$, and likewise using the autocorrelation functions for the estimate of $q$. extended autocorrelation functions (EACF) can be used to simultaneously determine $\mathrm{p}$ and $\mathrm{q}$. 
The commercialization of biofuels requires the design of an efficient supply chain network. Significant complexities in the BSC and the presence of uncertain variables therein have led to the paramount importance of the need for predicting the chain performance in the future to provide appropriate policies to increase the market share of biofuels. This article presented a MILP model for the design of a BSC network to minimize the total supply chain cost along the desired time horizon.

Several research studies have been conducted on the predictions and models of biofuel refinery selection with various solution techniques presented over the years. The ARMA model, also known as the Box-Jenkins model or method is commonly used in analysis and forecasting. This model was used in source [1] for non-renewability of these fuels method analysis and led to increased production of this product. In sources [2] and [3], the supply chain model is used for the optimal selection of Biomass as raw material. This model did not provide the ability to respond to large biomass resources and focused only on agricultural wastes. In Source [4], the same problem arose with lignocellulosic biomass. Source [6] reviewed the present refineries and provided recommendations for change to transport to a refinery. In source [21], based on modeling customer demand, refineries were designed and located. Source [23] worked with ARMA models is to use fuzzy time series. While in the present study, the ARMA time-based model is widely used

It was used as the most efficient forecasting method in biofuel sciences and was validated by a numerical equation. This model was revised and validated based on time series for biofuel sources with real data. Using ARMA to predict time series with uncertainty is essential because knowledge does not assume every basic model or relationship like some other method. ARMA relies primarily on predicting past values in this set as well as previous error terms. However, these ARMA models designed and introduced are relatively more robust and efficient than more complex structural models than short-term predictions.

In this chain, fuel demand is in a time series form and follows the ARMA process. In this paper, the effect of the ARMA time series structure for biofuel demand was investigated on the BSC design. In this regard, a numerical example was used to design an optimal BSC network. Using the ARMA predictor models for biofuel demand, an optimal supply chain was also designed for eight future periods to provide a broader insight into the more effective design of the BSC chain and to minimize its total cost.

\section{References}

[1] A.R. Zahedi, S. Labbafi, A. Ghaffarinezhad, K. Habibi, Design, construction and performance of a quintuple renewable hybrid system of wind/geothermal/biomass/solar/hydro plus fuel cell, Int. J. Hydrogen Energy. 46 (2021) 6206-6224. doi:10.1016/J.IJHYDENE.2020.11.188.

[2] M. Esmaeili Shayan, G. Najafi, F. Ghasemzadeh, Advanced Study of the Parabolic Trough Collector Using Aluminum (III) Oxide Seal, International Journal of Smart Grid - ijSmartGrid, Int. 4 (2020) 111-116. https://ijsmartgrid.org/index.php/ijsmartgridnew/article/ view/108/pdf.

[3] M.S. Esmaeili, G. Najafi, Energy-Economic Optimization of Thin Layer Photovoltaic on Domes and Cylindrical Towers, Int. J. Smart Grid - IjSmartGrid. 3 (2019)

84-91. https://www.ijsmartgrid.ijrer.org/index.php/ijsmartgridn ew/article/view/61.

[4] F. Wang, D. Ouyang, Z. Zhou, S.J. Page, D. Liu, X. Zhao, Lignocellulosic biomass as sustainable feedstock and materials for power generation and energy storage, J. Energy Chem. 57 (2021) 247-280. doi:10.1016/j.jechem.2020.08.060.

[5] J. Knápek, T. Králík, K. Vávrová, J. Weger, Dynamic biomass potential from agricultural land, Renew. Sustain. Energy Rev. $134 \quad$ (2020) 110319. doi:10.1016/j.rser.2020.110319.

[6] M. Esmaeili shayan, Solar Energy and Nuclear Power. Economic Requirements and Hindrances, München, GRIN Verlag, (2020). https://www.grin.com/document/922228.

[7] M. Esmaeili Shayan, Solar Energy and Its Purpose in Net-Zero Energy Building, Zero-Energy Build. New Approaches Technol., IntechOpen Inc, 2020. doi:10.5772/intechopen.93500.

[8] F. Ghasemzadeh, M. Esmaeilzadeh, M. Esmaeili shayan, Photovoltaic Temperature Challenges and Bismuthene Monolayer Properties, Int. J. Smart Grid. 4 (2020) 190195.

https://www.ijsmartgrid.org/index.php/ijsmartgridnew/a rticle/view/131/pdf.

[9] S.M. Zahraee, N. Shiwakoti, P. Stasinopoulos, Biomass supply chain environmental and socio-economic analysis: 40-Years comprehensive review of methods, decision issues, sustainability challenges, and the way forward, Biomass and Bioenergy. 142 (2020) 105777. doi:10.1016/j.biombioe.2020.105777.

[10] F. Sun, S.C. Sarin, J.S. Cundiff, I.O. Sert, Design of costeffective sorghum biomass feedstock logistics-A comparison of different systems, Biomass and Bioenergy. $\quad 143 \quad$ (2020) 105823. doi:10.1016/j.biombioe.2020.105823.

[11] Biomass sustainability criteria: Greenhouse gas accounting issues for biogas and biomethane facilities, Energy Policy. $87 \quad$ (2015) 95-109. doi:10.1016/J.ENPOL.2015.08.031.

[12] R.M. De Mol, M.A.H. Jogems, P. Van Beek, J.K. Gigler, Simulation and optimization of the logistics of biomass fuel collection, Netherlands J. Agric. Sci. 45 (1997) 219 228. doi:10.18174/njas.v45i1.535.

[13] M. Sharifzadeh, M. Sadeqzadeh, M. Guo, T.N. Borhani, N.V.S.N. Murthy Konda, M.C. Garcia, L. Wang, J. Hallett, N. Shah, The multi-scale challenges of biomass fast pyrolysis and bio-oil upgrading: Review of the state of art and future research directions, Prog. Energy $\begin{array}{lllll}\text { Combust. } & \text { Sci. } & 71 & \text { (2019) }\end{array}$ 
doi:10.1016/j.pecs.2018.10.006.

[14] M. Rabbani, S. Momen, N. Akbarian-Saravi, H. Farrokhi-Asl, Z. Ghelichi, Optimal design for sustainable bioethanol supply chain considering the bioethanol production strategies: A case study, Comput. $\begin{array}{llll}\text { Chem. } & \text { Eng. } & 134 & \text { (2020) } \\ & 106720 .\end{array}$ doi:10.1016/j.compchemeng.2019.106720.

[15] B. Theozzo, M. Teles dos Santos, A MILP framework for optimal biorefinery design that accounts for forest biomass dynamics, Comput. Chem. Eng. 146 (2021) 107201. doi:10.1016/j.compchemeng.2020.107201.

[16] M. Dal-Mas, S. Giarola, A. Zamboni, F. Bezzo, Strategic design and investment capacity planning of the ethanol supply chain under price uncertainty, Biomass and Bioenergy. $\quad 35 \quad$ (2011) 2059-2071. doi:10.1016/j.biombioe.2011.01.060.

[17] S. Giarola, N. Shah, F. Bezzo, A comprehensive approach to the design of ethanol supply chains including carbon trading effects, Bioresour. Technol. 107 (2012) 175-185. doi:10.1016/j.biortech.2011.11.090.

[18] C. Koutlis, S. Papadopoulos, M. Schinas, I. Kompatsiaris, LAVARNET: Neural network modeling of causal variable relationships for multivariate time series forecasting, Appl. Soft Comput. J. 96 (2020) 106685. doi:10.1016/j.asoc.2020.106685.

[19] S. Huang, A. Potter, D. Eyers, Using simulation to explore the influence of online reviews on supply chain dynamics, Comput. Ind. Eng. (2020) 106925. doi:10.1016/j.cie.2020.106925.

[20] K. Gilbert, An ARIMA supply chain model, Manage. Sci. 51 (2005) 305-310. doi:10.1287/mnsc.1040.0308.

[21] M. Azadbakht, E. Esmaeilzadeh, M. Esmaeili-Shayan,
Energy consumption during impact cutting of canola stalk as a function of moisture content and cutting height, J. Saudi Soc. Agric. Sci. 14 (2015) 147-152. doi:10.1016/j.jssas.2013.10.002.

[22] H.L. Lee, V. Padmanabhan, S. Whang, Information distortion in a supply chain: The bullwhip effect, Manage. Sci. 50 (2004) 1875-1886. doi:10.1287/mnsc. 1040.0266 .

[23] F.T.S. Chan, A. Samvedi, S.H. Chung, Fuzzy time series forecasting for supply chain disruptions, Ind. Manag. Data Syst. 115 (2015) 419-435. doi:10.1108/IMDS-072014-0199.

[24] H.I. Cobuloglu, I.E. Büyüktahtakin, A mixed-integer optimization model for the economic and environmental analysis of biomass production, Biomass and Bioenergy. 67 (2014) 8-23. doi:10.1016/j.biombioe.2014.03.025.

[25] Q.A. Nguyen, W.A. Smith, B.D. Wahlen, L.M. Wendt, Total and Sustainable Utilization of Biomass Resources: A Perspective, Front. Bioeng. Biotechnol. 8 (2020) 546. doi:10.3389/fbioe.2020.00546.

[26] H.L. Teo, R.A. Wahab, Towards an eco-friendly deconstruction of agro-industrial biomass and preparation of renewable cellulose nanomaterials: A review, Int. J. Biol. Macromol. 161 (2020) 1414-1430. doi:10.1016/j.ijbiomac.2020.08.076.

[27] D. Abbasi, M. Ashrafi, S.H. Ghodsypour, A multi objective-BSC model for new product development project portfolio selection, Expert Syst. Appl. 162 (2020). doi:10.1016/j.eswa.2020.113757.

[28] M. Azadbakht, M.E. Shayan, H. Jafari, E. Ghajarjazi, A. Kiapei, Factor Resistance Comparison of a Long Shaft in 955 and 1055 John Deere Grain Combine, (2015). doi:10.5281/ZENODO.1100909. 